\title{
Life's work: occupational health - the wealth of the nation
}

\begin{abstract}
'When a doctor arrives to attend some patient of the working class he ought not to feel his pulse the moment he enters, as is nearly always done without regard to the circumstances of the man who lies sick ... I may venture to add one more question: What occupation does he follow?"
\end{abstract}

It is estimated that $60 \%$ of the working populations' waking life is consumed by work. Work and health are symbiotically interweaved. A patient's health affects their ability to get a job and to retain it. In Britain, $7.5 \%$ of the population receive incapacity benefit, and worklessness itself is strongly linked to elevated risk of morbidity and social inequality. Individuals bring their burdens, aspirations, and vulnerabilities to the workplace. In turn, the work milieu itself is a major influence on life outside the hours of employment. Occupation can also be associated with hazards that can produce disease and injury and up to $38 \%$ of patients attending for consultations in primary care report an occupational dimension to their condition. ${ }^{2}$

Occupational medicine builds on a framework of general medicine and requires awareness of industrial hygiene, epidemiology, toxicology, and health and safety legislation, but paramount is the necessity to elucidate and comprehend the nature of work, exposures, and workplace environment to which their patients belong and promote healthy and safe working practises. Physicians in this field have a dual obligation to employer and to employee. They must strike a professional nonchalance between having the employee as a patient, while addressing the needs of the employer, government, and wider society. A developed sense of institutional awareness is also essential, and a cognisance that decisions to hire and fire can be influenced by company doctor reports.
Sickness absenteeism in the UK is a significant financial burden costing in excess of $£ 100$ billion per annum, ${ }^{3}$ which is greater than the entire annual NHS budget and equivalent to the gross domestic product (GDP) of Portugal. Recognition of this socioeconomic blight has led to the government professing an interest in occupational health, but until recently these recommendations were more form than substance. The report Working Together suggested several key objectives for the NHS, in particular to achieve 'year on year improvement in sickness absenteeism rates' and 'to provide occupational health services to all NHS employees'. ${ }^{4}$ In 2001, the Occupational Health Advisory Committee of the Health and Safety Commission made recommendations that more research should be directed towards raising the profile of occupational health, identifying causes of sickness absence, and the economic benefits of occupational health intervention, with the expectation that these services would be provided by existing physicians and nurses in primary care, without consideration of additional training needs. ${ }^{5}$

Norway has a national sickness benefit register, which is used to provide statistics on the medical causes and prevalence of sickness absence from work to guide occupational health physicians and those who hold the purse strings. A study by Skøien et al, ${ }^{6}$ used this database to examine the incidence of sickness absence caused by dizziness and vertigo, as documented by the doctors signing the sickness certificate. The group reports that although dizziness and vertigo are responsible for only a small number of short-term spells of sickness absence, a significant proportion of incapacity benefits are awarded for these conditions. Identification of trends such as this is paramount if we are to cut back on the costs of a sick workforce.

This year, Dame Carol Black, the
National Director for Health and Work, called for an urgent and comprehensive reform of health and work in Britain in the report Working for a Healthier Tomorrow. ${ }^{2}$ One of the major changes particularly pertinent for GPs is a radical overhaul of the certification system where the traditional Med-3 sicknote system will soon be replaced with an Absence Advice Note (AAN). The AAN focuses on what people can continue to do, rather than what they cannot, with a move towards getting people back to work sooner.

Despite the fact we spend the majority of our lives at work, only between one- to two-thirds of the UK workforce have access to specialist occupational health service providers. The majority of the UK population have access to a GP and it is in the primary care setting where the contemporary iceberg of occupational medicine floats.

The Health and Occupation Reporting Network for GPs (THOR-GP) is a new electronic online reporting system designed specifically for primary care physicians as a surveillance tool to define the incidence of occupational disease in primary care. The project has been running since 2006, and the group have published their first two calendar years of data. ${ }^{7}$ During this period 2.2 million people self-reported ill health accounting for 36 million days lost: musculoskeletal and psychiatric disorders were the commonest diagnoses.

With the focus on reform it is not yet clear how we will meet the future needs of our workers. Society measures economic success in terms of high levels of employment, growth in industry, and GDP. More needs to be done to prevent work damaging health, promote the health of those at work, and promote work for those with health problems.

Many key challenges lie ahead and GPs are likely to remain at the frontline of medical decision making regarding health issues in life and work. Therefore, there is an onus to ensure that GPs interested in 
practising occupational medicine have the encouragement, guidance, support, and access to training. Planning and supporting return to work in partnership with patients and specialists is a key component of clinical management. The NHS needs to be funded to ensure the workforce, on which the livelihood of the country depends, is treated promptly when ill. The realisation that work is good for health suggests that staying in work, and returning to work, needs to be part of the prescribed treatment of ill health.

\section{Steven E Bradshaw,}

London.

\section{REFERENCES}

1. Ramazzini B. De Morbis Artificum (2nd Latin edn, 1713). [Trans. Wright WC. Diseases of workers. Chicago, IL: University of Chicago Press, 1940.

2. Weevers HJ, van der Beek AJ, Anema JR, et al. Workrelated disease in general practice: a systematic review. Fam Pract 2005; 22(2): 197-204.

3. Black C. Working for a healthier tomorrow. London: TSO, 2008:

http://www.workingforhealth.gov.uk/documents/wo rking-for-a-healthier-tomorrow-tagged.pdf (accessed 6 Aug 2008).

4. Department of Health. Working together. Securing a quality workforce for the NHS. London: Department of Health, 1998.

5. Occupational Health Advisory Committee. Report and recommendations on improving access to occupational health support. London: HSC, 2000

\section{Further information.}

Education and Continuing Professional Development

- The Society of Occupational Medicine (SOM) is available to all doctors with an interest in occupational health: https://www.som.org.uk/

- Higher specialist training in occupational health is supervised by the Faculty of Occupational Medicine (FOM), based at the Royal College of Physicians: http://www.facoccmed.ac.uk/

- Distance learning Occupational Medicine Diploma courses are available at the Centre for Occupational and Environmental Health from the University of Manchester: www.coeh.man.ac.uk/ and the Institute of Occupational and Environmental Medicine at Birmingham University: http://www.pcpoh.bham.ac.uk/ioem/

National and regional occupational health resources

- The Health and Safety Executive (HSE) oversees health and safety in a wide range of working environments including factories, hospitals and schools: http://www.hse.gov.uk/

- England: NHS Plus is a network of NHS Occupational Health Departments that provides occupational health services to both NHS and non-NHS organisations in England: http://www.nhsplus.nhs.uk. Scotland: http://www.healthyworkinglives.com/

Wales: http://www.hse.gov.uk/workplacehealth/workboostwales/index.htm Northern Ireland: Employment Medical Advisory Service (EMAS): http://www.hseni.gov.uk/

- The Health Work and Wellbeing Initiative website has further guidance information for both GPs and employers throughout the UK: http://www.workingforhealth.gov.uk

6. Skøien A, Wilhemsen K, Gjesdal S. Occupational disability caused by dizziness and vertigo: a register-based prospective study. Br J Gen Pract 2008; 58: 619-623.

7. Hussey L, Turner S, Thorley K, et al. Work-related ill health in general practice, as reported to a UK-wide surveillance scheme. Br J Gen Pract 2008; 58: 637-640.

DOI: 10.3399/bjgp08X330690

\section{ADDRESS FOR CORRESPONDENCE}

Steven E Bradshaw,

20 Candlemakers Apartments,

112 York Road, London, SW11 3RS.

E-mail: stevenb117@hotmail.co.uk 